\title{
Adhesion of human enterotoxigenic Escherichia coli to human mucus secreting HT-29 cell subpopulations in culture
}

\author{
S Kerneis, M F Bernet, M H Coconnier, A L Servin
}

\begin{abstract}
Enterotoxigenic Escherichia coli (ETEC) bearing the fimbrial colonisation factor antigens CFA/I, CFA/II, CFA/II, and the non-fimbrial antigen 2230 were tested for their ability to adhere to two cultured human intestinal HT-29 mucus secreting cell subpopulations. These populations are referred to as HT29-MTX and HT29-FU, which differ in the amount of secreted mucins and in their gastric or colonic mucin immunoreactivity respectively. Adherence of radiolabelled bacteria to cell monolayers infected apically was assessed. All ETEC strains adhered to the mucus secreting HT29-FU subpopulation, which secretes mucins of colonic immunoreactivity. Visualisation of bacteria by scanning electron microscopy showed that ETEC bound to the HT29-FU cells possessing a brush border, but not to the mucus and that ETEC binding developed as a function of cell differentiation. The adhesion of ETEC to cells possessing a brush border and to mucus secreting cells was also analysed by indirect immunofluorescence in HT29-MTX cells, which secrete mucins of gastric immunoreactivity. Fluorescein isothiocyanate labelling using specific anti-CFA/I antibody was used to show ETEC; rhodamine isothiocyanate labelling using a monoclonal antibody (designated M1) against purified human gastric mucus was used to detect secreted mucins, and rhodamine isothiocyanate labelling using a monoclonal antibody (designated 4H3) against human dipeptidylpeptidase IV was used to show cells possessing a brush border. Binding of bacteria colocalised with dipeptidylpeptidase IV of enterocytes and not with mucins.

(Gut 1994; 35: 1449-1454)
\end{abstract}

Adherence of bacteria to epithelial intestinal cells is an important prerequisite for colonisation by micro-organisms and virulence manifestations. ${ }^{12}$ To remain associated with the gut mucosa and to withstand the flow of the intestinal chyme, bacteria have developed several mechanisms of association. In particular, pathogenic bacteria form close associations with the intestinal mucosa and their inability to do so results in rapid elimination from the gut. Moreover, bacteria trapped in the surface mucus, coupled with peristalsis, results in the rapid expulsion of bacteria from the intestine.

Two major cell phenotypes - that is, enterocytes and goblets cells - are represented in the intestinal mucosa. The brush border of enterocytes is the target of many pathogenic bacteria. ${ }^{2}$ The human small intestinal mucosa has a mucus coating at the surface. In vivo, for some pathogenic bacteria the mucus gel could serve at least two functions. ${ }^{3}$ Firstly, it might be a source of nutrients for bacterial growth, thus influencing positively the intestinal colonisation by the adhering bacteria, which have the ability to survive in and multiply in the outer areas of the mucus layer. Secondly, the mucus coat overlying the microvillous surface contributes to host defence by preventing bacterial adhesion or invasion and toxin binding to the mucosal surface. ${ }^{4}$

The role of mucus in enterotoxigenic Escherichia coli (ETEC) colonisation is an important question to investigate. In this study, we describe the use of the recently described mucus secreting HT29-MTX ${ }^{5}$ and HT29-FU 6 cell subpopulations as human cell models to study in vitro adhesion of enterotoxigenic $E$ coli expressing colonisation factor antigens CFA/I, CFA/II, CFA/III or 2230 antigen adhesive factors. Binding assay of ${ }^{14} \mathrm{C}$-radiolabelled ETEC was used to assess adhesion. Attachment of ETEC onto mucus secreting cells was visualised by scanning electron microscopy and by indirect immunofluorescence labelling with polyclonal antibodies directed against purified CFA factors, whereas intestinal mucus was shown using a monoclonal antibody directed against human mucins.

\section{Methods}

\section{CELL CULTURE}

We used two mucus secreting HT-29 cell subpopulations selected from the parental mainly undifferentiated HT-29 cell line ${ }^{7}$ by growth adaptation to, (a) methotrexate $\left(10^{-6} \mathrm{M}\right)$ referred to as $\mathrm{HT}_{29-\mathrm{MTX}^{5} \text {, and }}$ (b) 5-fluoruracil $\left(10^{-5} \mathrm{M}\right)$ referred to as HT29-FU6 (A Zweibaum, INSERM Unité 178 Différenciation Cellulaire Intestinale, 94807 Villejuif, France). The two subpopulations remain stable when they are subcultured under standard conditions - that is, in standard glucose containing medium. ${ }^{5}$ Cells were routinely grown in Dulbecco modified Eagle's minimal essential medium 
(25 mM glucose) (Eurobio, Paris, France), supplemented with $10 \%$ inactivated (30 minutes, $56^{\circ} \mathrm{C}$ ) fetal bovine serum (Boehringer $\mathrm{GmbH}$, Mannheim, Germany). ${ }^{8}$ Monolayers of cells were prepared on glass coverslips, which were placed in six well tissue culture plates (Corning Glass Works, Corning, NY). For bacterial binding assay, HT-29 cells were grown in 24 well tissue culture plates (Corning Glass Works, Corning, NY). Cells were seeded at a density of $2 \times 10^{4}$ cells per $\mathrm{cm}^{2}$. For maintenance purposes, cells were passaged weekly using $0.25 \%$ trypsin in $\mathrm{Ca}^{2+} \mathrm{Mg}^{2+}$ free phosphate buffered saline (PBS) containing $0.53 \mathrm{mM}$ EDTA. Experiments and maintenance of the cells were carried out at $37^{\circ} \mathrm{C}$ in a $10 \%$ $\mathrm{CO}_{2} / 90 \%$ air atmosphere. The culture medium was changed daily. Unless otherwise stated, cultures were used at late postconfluence - that is, after 20 days in culture.

BACTERIAL STRAINS, GROWTH CONDITIONS, AND RADIOLABELLING

The strains of ETEC used were: H10407 expressing colonisation factor antigen I (CFA/I), Pb176 expressing CFA/II (Cs1 and Cs3), 1373 expressing CFA/III, and 2230 expressing the non-fimbrial 2230 antigen. ${ }^{9}$ The bacteria were stored in CFA glycerol broth at $-80^{\circ} \mathrm{C}$. Before adherence assays, all strains were grown on $2 \%$ CFA agar containing $1 \%$ casamino acids (Difco Laboratories, Detroit, MI), $0.15 \%$ yeast extract, $0.005 \%$ magnesium sulphate, and $0.0005 \%$ manganese chloride for 18 hours at $37^{\circ} \mathrm{C}$.

Bacteria were metabolically labelled by the addition of ${ }^{14} \mathrm{C}$-acetic acid (Amersham, 94 $\mathrm{mCi} / \mathrm{mmol} ; 100 \mu \mathrm{Ci} / 10 \mathrm{ml}$ tube) as previously described. ${ }^{10}$

\section{ADHERENCE ASSAY}

The method used for determination of adherence of ETEC to HT-29 cells was that described elsewhere for Caco-2 cells. $^{9} 10$ Briefly, HT-29 monolayers were gently washed twice with PBS before infection. ${ }^{14} \mathrm{C}$-radiolabelled $E$ coli cells were suspended in the culture medium and $2 \mathrm{ml}\left(10^{8}\right.$ $\mathrm{CFU} / \mathrm{ml}$ ) of this suspension was added to each well of the tissue culture plate. The plates were incubated at $37^{\circ} \mathrm{C}$ in $10 \%$ $\mathrm{CO}_{2} / 90 \%$ air for one hour. The monolayers were then washed gently five times with sterile PBS. Adhering bacteria and HT-29 cells were dissolved in a one tenth normal $\mathrm{NaOH}$ solution. The amount of bacterial adhesion was evaluated by liquid scintillation counting (background less than $0.05 \%$ ). Each adherence assay was conducted in triplicate on three successive HT-29 cell passages.

ANTIBODIES

A pool of mAbs reactive with mucin $M 1$ epitopes of gastric mucins ${ }^{11}$ has also been reported to recognise gastric mucins secreted by the colonic HT29-MTX cells. ${ }^{12}$ A sample of this $\mathrm{mAb}$ pool was obtained from Dr J Bara (INSERM U55, Paris). mAb 4H3 against the human dipeptidylpeptidase IV (EC 3.4.14.5) was obtained from Dr S Maroux (Centre de Biochimie et de Biologie Moléculaire, Marseille). ETEC whole cells were shown using polyclonal rabbit antibodies raised against purified ETEC CFA/II ${ }^{10}$ obtained from Dr A Darfeuille-Michaud (Laboratoire de Microbiologie, Université Clermont I).

\section{IMMUNOFLUORESCENCE}

Adhering $E$ coli, mucins, and dipeptidylpeptidase IV were shown in unpermeabilised cell layers by indirect immunofluorescent labelling. Cell layers were fixed ( 15 minutes at room temperature) in either paraformaldehyde (3.5\% in PBS $\mathrm{Ca}^{2+} \mathrm{Mg}^{2+}$ free) or ethanol, as described by Lesuffleur et al. ${ }^{5}$ Fluorescein and rhodamine coupled goat antiglobulins were from Institut Pasteur Productions (Paris, France). Immunolabelling was examined with a Leitz Aristoplan microscope with epifluorescence. All photographs were taken on Kodak T-MAX 400 black and white film (Eastman Kodak Co, Rochester, NY).

\section{SCANNING ELECTRON MICROSCOPY}

For scanning electron microscopy, cells were grown on glass coverslips. After the bacterial adhesion assay, cells were fixed with $2.5 \%$ glutaraldehyde in $0 \cdot 1 \mathrm{M}$ phosphate buffer (pH 7.4) at $24^{\circ} \mathrm{C}$ for one hour. After five washes with phosphate buffer, cells were postfixed for 30 minutes with $2 \%$ osmium tetroxide, washed three times with the $0 \cdot 1 \mathrm{M}$ phosphate buffer, and dehydrated in a graded series (30 to $100 \%$ ) of ethanol. Cells were dried after substitution with liquid carbon dioxide (Balzers CPD030, Hudson, $\mathrm{NH}$ ) and coated with gold. The specimens were then examined with a scanning Jeol JSM 25S electron microscope.

\section{Results}

CHARACTERISTICS OF THE HUMAN MUCUS SECRETING HT29-MTX AND HT29-FU CELL SUBPOPULATIONS

Figures 1 and 2 show the morphological characteristics of the two mucus secreting HT-29 cell subpopulations - that is, HT29-MTX and HT29-FU cells - used here to study the cell association of enterotoxigenic E coli.

Visualisation of the cell surface of the HT29-FU cells at late confluency (20 days of culture) by scanning electron microscopy (Fig 1) shows that this cell subpopulation is largely composed of enterocyte like cells with an apical brush border (Fig 1A) and of randomly distributed goblet cells that secrete mucus blebs (Fig 1A and B). The brush border of fluid transporting cells in HT29-FU cells resembles that seen in differentiated enterocyte like HT-29 cells. $^{813}$ As previously reported, ${ }^{6}$ 

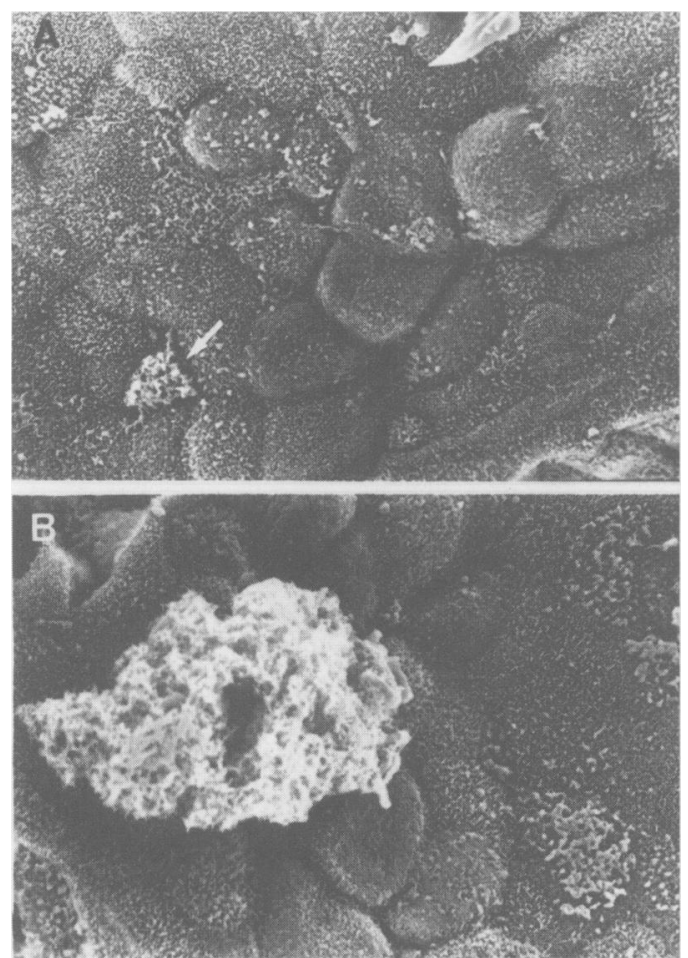

Figure 1: Scanning electron micrographs of the cultured human intestinal HT29-FU cells. (A) Low magnification showing fluid transporting cells with a brush border and of randomly distributed goblet cells (arrow); (B) high

magnification showing mucus secreted by the goblet cells.

the mucins secreted by the HT29-FU cells react with antibodies against colonic mucins (not shown).

Examination by scanning electron microscopy of the cell surface of the globlet cells HT29-MTX at late confluency (20 days of culture) shows that the cells produce comparatively large amounts of mucus (Fig 2). Higher magnification shows a dense mucus gel (Fig 2A) with numerous mucus buds (Fig 2B). This mucus gel is labile, however, and after extensive washes a brush border is seen at the cell surface (Fig 2C). As previously reported, ${ }^{5} 1214$ the brush border of these cells is endowed with intestinal differentiation associated hydrolases such as dipeptidylpeptidase IV, and mucins are of gastric immunoreactivity (see Fig 5).

ATTACHMENT OF ETEC TO THE HUMAN MUCUS SECRETING HT-29 CELL SUBPOPULATIONS

The HT29-FU cell line has the advantage of closely mimicking in vitro the situation present in vivo where the two cell phenotypes - that is, enterocyte like and mucus secreting - are present. Human $E$ coli strains harbouring $\mathrm{CFA} / \mathrm{I}, \mathrm{CFA} / \mathrm{II}$ (Cs1 + Cs3), CFA/III, and 2230 antigen adhesive factors were incubated with cell monolayers to evaluate their abilities to adhere to the fluid transporting and the mucus secreting cells. Quantitative binding assay entailing the incubation of a fixed concentration of radiolabelled ETEC bacteria $\left(10^{8} \mathrm{CFU} / \mathrm{ml}\right)$ with cultured cells was performed. Bacterial adhesion was expressed as the percentage of the incubated bacteria remaining associated with the adhering microorganisms and the cells after washing. All
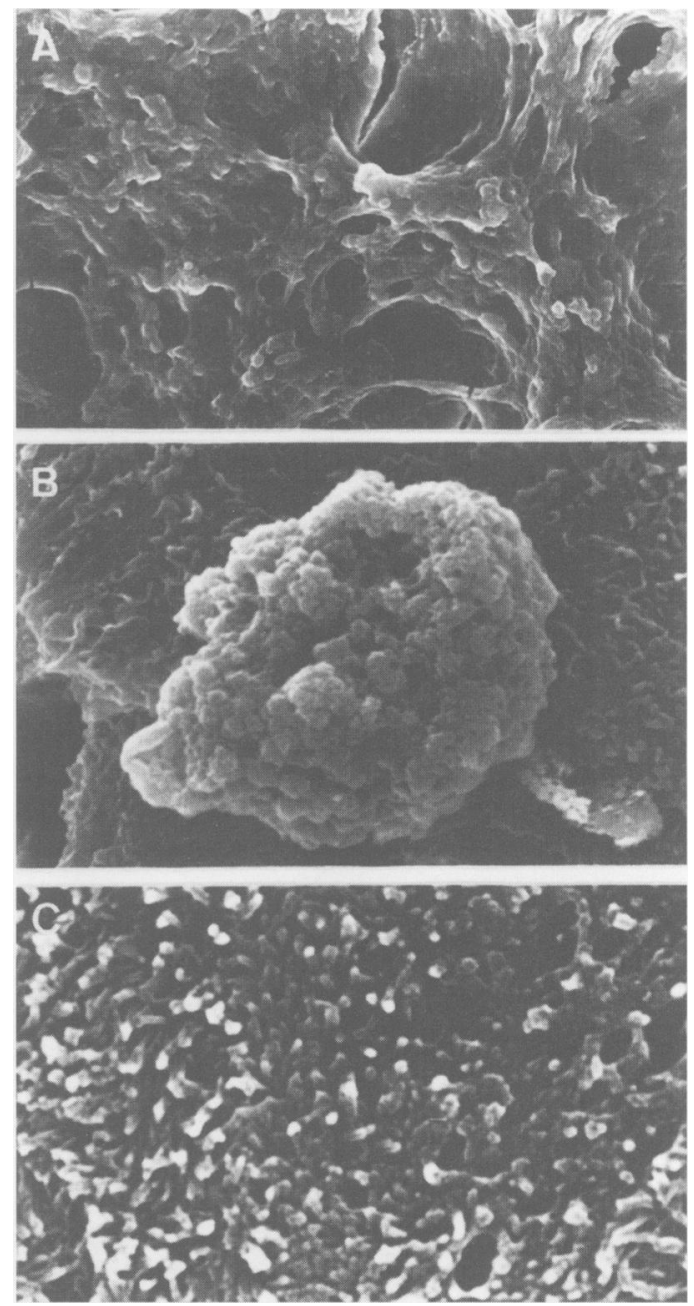

Figure 2: Scanning electron micrographs of the cultured human intestinal HT29-MTX cells. (A) Low magnification showing the dense mucus gel at the cell surface; (B) high magnification showing budding of mucus; (C) high magnification showing brush border after elimination of mucus by extensive washes.

ETEC strains bind to the HT29-FU cell subpopulation. Low values (mean (SD)) of adhesion were seen for ETEC strains bearing CFA/III $(1.82(0.09))$ or 2230 antigen $(1.46$ (0.05)), compared with adhesion of ETEC harbouring CFA/I $(4 \cdot 10(0 \cdot 30))$ or CFA/II $(3.78(0.45))$. As disclosed by scanning electron microscopy, no binding occurred to the colonic mucus secreted by the HT29-FU goblet cells (Fig 3A), whereas ETEC bound to the cells possessing a brush border (Fig 3B).

It has been reported that for intestinal cell lines established from the parental HT-29 cell line, ${ }^{7}$ the appearance of a brush border and the apical expression of brush border components are a growth related phenomenon. ${ }^{15} \mathrm{We}$ therefore examined the adhesion of ETEC as it relates to the intestinal differentiation of HT29-FU cells. No adhesion appeared during the first days of culture. Adhesion of ETEC appeared after confluency and increased during subsequent days (Fig 4). As ETEC bind in preference to the brush border of the enterocytic cells in the HT29-FU cell subpopulation, this result suggests that the brush border expression of functional ETEC binding sites is a growth related phenomenon. This result is consistent with our previous finding showing 


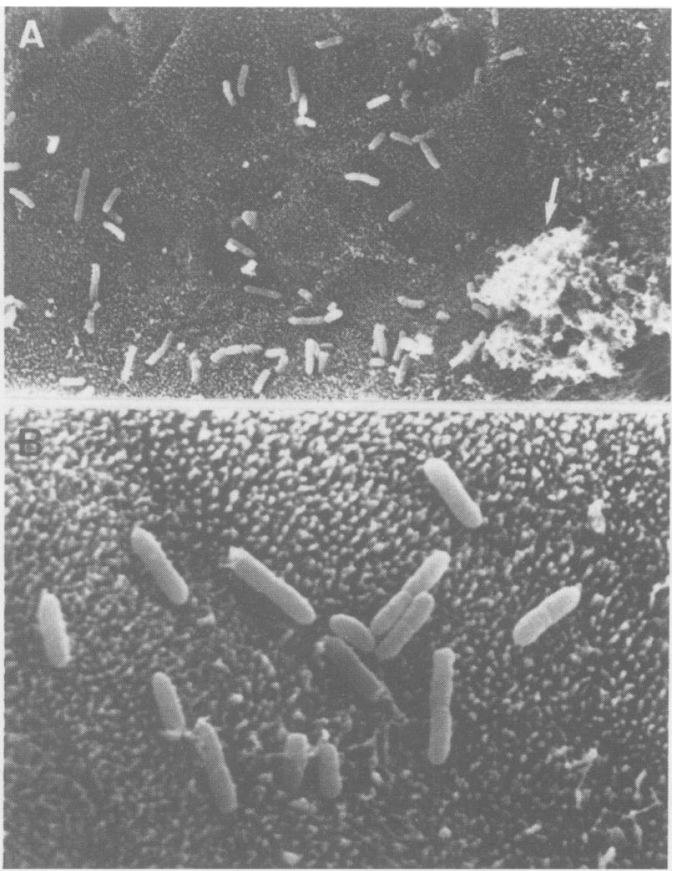

Figure 3: Scanning electron micrographs of HT29-FU cell monolayers infected apically with enterotoxigenic $\mathbf{E}$ coli (ETEC). (A) Low magnification micrograph of

HT29-FU cells showing adhesion of ETEC harbouring $C F A / I$ adhesin to cell possessing brush border, whereas no adhesion occurs to mucus secreted by the goblet cells (arrow); (B) high magnification of adhesion of ETEC $C F A / I$ on brush border in fluid transporting cells. Bacterial binding to the microvilli takes place without damage to the underlying cell population.

that brush border ETEC binding to the human cultured enterocyte like HT-29 and Caco-2 cells develops as a function of cell differentiation. ${ }^{9} 10$

ETEC binding was also examined using the HT29-MTX cells. Because at post-confluent culture (20 days) the cell monolayer is covered by a large amount of mucins that cover the brush border, these cells were examined at an earlier period of the culture (seven days) - that is, when all the cells express an apical brush border but only a limited amount of mucus is secreted on the cell surface. ${ }^{1214}$ Immunofluorescence study of unpermeabilised HT29-MTX cells at seven days in culture showed the presence of mucus secretion (Fig 5B) and dipeptidylpeptidase IV (Fig 5E). Colocalisation comparisons were conducted - that is, ETEC (Fig 5A) and mucins (Fig 5B) - as well as ETEC (Fig 5D) and dipeptidylpeptidase IV (Fig 5E). ETEC binding clearly did not colocalise with mucins (Fig 5C), whereas it did colocalise with dipeptidylpeptidase IV (Fig 5F).

\section{Discussion}

A number of studies have been performed using in vitro models to study the role of the mucus layer in bacterial growth, adhesion, and colonisation. These models consist of crude or purified mucus, which have been used to study positive adhesion of human pathogenic bacteria, such as the enterohaemorrhagic $E$ coli strain CL-49, 1617 Yersinia enterocolitica, ${ }^{18} 19$ and Campylobacter jejuni. ${ }^{20}$ Fresh and formalin fixed isolated human ileal segments containing goblet cells producing mucus and purified human mucus have been used to study the adhesion of Helicobacter pylori, ${ }^{21}$ enterovirulent $E$ coli, $^{2223}$ and Pseudomonas aeruginosa. ${ }^{24}$ Human tracheobronchial mucins have been used to study adhesion of Pseudomonas aeruginosa $^{2425}$ and cepacia. ${ }^{26}$

Studies concerning the development of pathogenicity of human ETEC require appropriate cellular models that closely mimic the cells participating in vivo in intestinal infection. Indeed, ETEC that attach to the epithelium by means of specific fimbrial or non-fimbrial adhesions, ${ }^{27}$ exhibit high tissue and host specificities. ${ }^{9} 10$ Adhesion of human ETEC has been studied using human, freshly isolated enterocytes. ${ }^{28}$ These enterocytes, however, are unstable in the laboratory. In the absence of normal cultured intestinal cells, various investigators have started to use cultured human intestinal cell lines to circumvent this problem. The parental mainly undifferentiated HT-29 cell population (HT-29 Std) ${ }^{7}$ contains a small proportion of enterocyte like ${ }^{510}$ and mucus secreting 5 cells. Several laboratories have isolated from HT-29 Std cells various differentiated HT-29 cell subpopulations and clones that can express in culture the differentiation characteristics of columnar absorptive cells. 8132930 Enterocyte like HT-29 cell subpopulations have been extensively used to study the organisation and function of human intestinal cells. ${ }^{15}$ Moreover, they closely mimic in vitro infection conditions by pathogens involved in human diarrhoea such as ETEC, ${ }^{91031-33}$ diffusely adhering $E$ coli, $^{34}$ and virus. ${ }^{35} 36$

In vivo ETEC can attach to carbohydrate structures acting as receptors on the thick mucus layer, composed of mucins and a large number of smaller associated proteins, that cover the intestinal cell surface. ${ }^{337}$ The role of the mucus gel in promoting bacterial colonisation has been shown for non-pathogenic and pathogenic animal and human $E$ coli using animal models. ${ }^{4}$ Recently, Sajjan and Forstner showed that enterohaemorrhagic $E$ coli serotype O157:H7 strain CL-49 bound to isolated

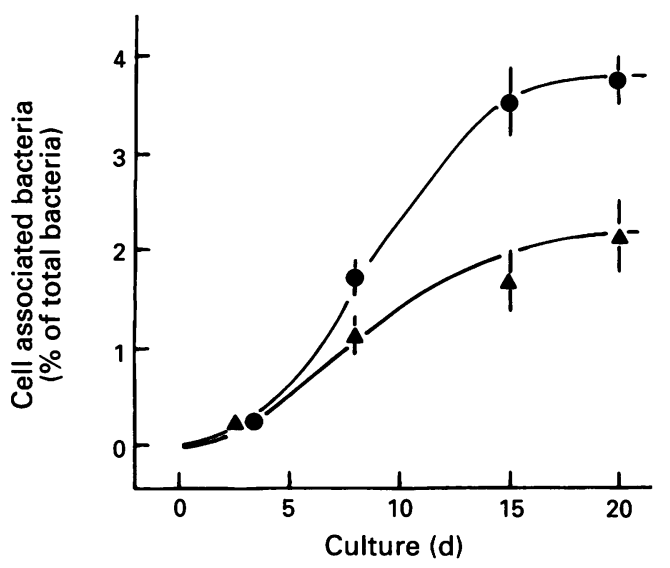

Figure 4: Development of adhesion of enterotoxigenic $\mathrm{E}$ coli harbouring $C F A / I I(0)$ and $C F A / I I I(\Delta)$ adhesive factors as a function of the days in culture of HT29-FU cells. Mean per cent of total radiolabelled ETEC bacteria adhering to the cell monolayer. Adherence assays were conducted in duplicate with three successive cell passages. Vertical bars indicate standard deviations. 

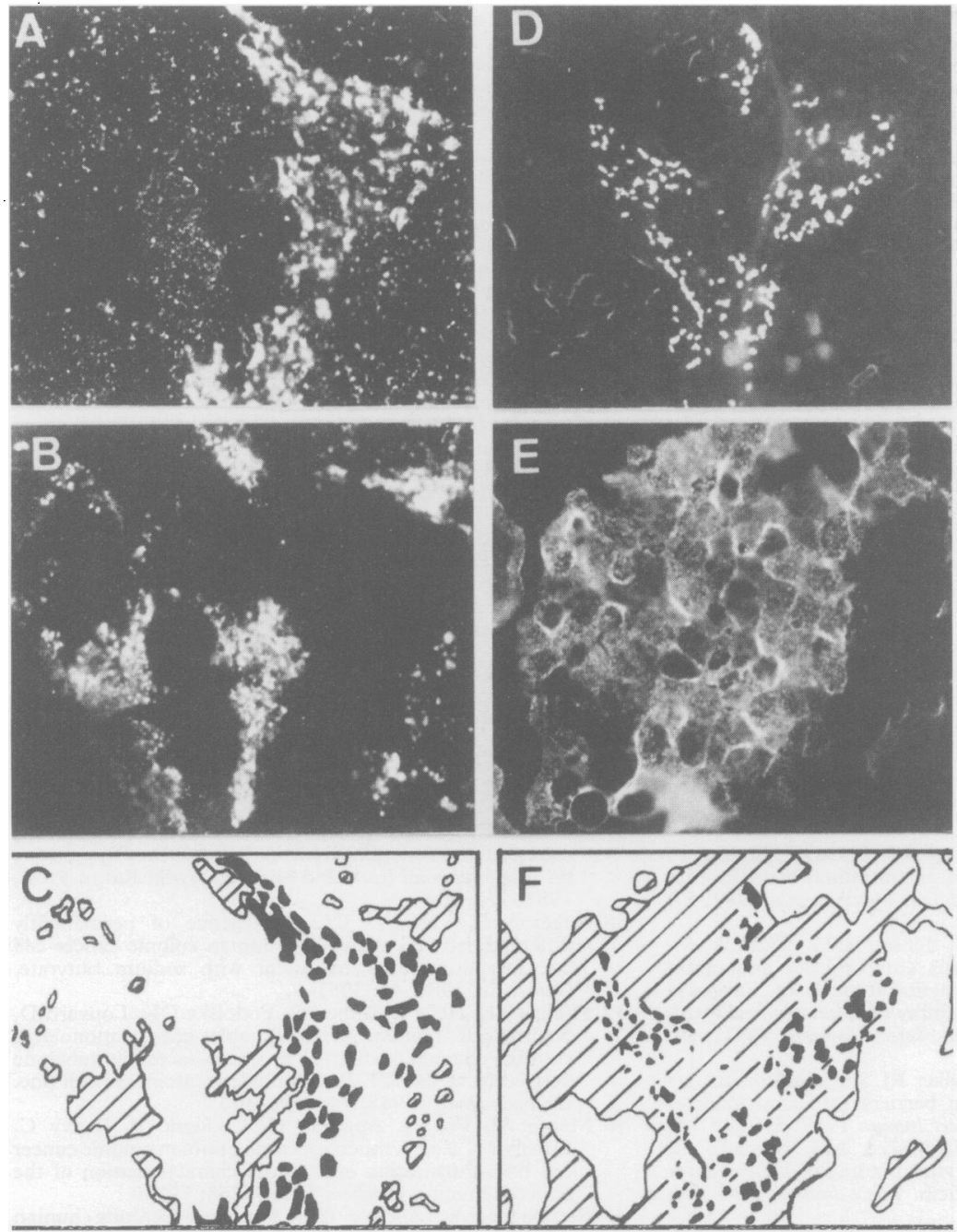

Figure 5: Cell localisation of ETEC CFA/I binding to cultured human intestinal HT29-MTX cells. Binding of ETEC whole cells (A) shown by indirect immunofluorescence staining using anti-CFA/I antibody and costaining of the cells with monoclonal antibody directed against gastric like mucins (B). In C, comparison between ETEC whole cells binding (black area) seen in $A$ and mucus staining (hatched area) seen in $B$. Note that ETEC binding occurs in an area of the cell layer without positive mucus reactivity. Binding of ETEC whole cells (D) shown by indirect immunofluorescence staining using anti-CFA/I antibody and costaining of the cells with monoclonal antibody directed against dipeptidylpeptidase IV $(E)$. In $F$, comparison between ETEC whole cells binding (black area) seen in $D$ and dipeptidylpeptidase IV staining (hatched area) seen in $E$. Note that ETEC binding occurs in an area of the cell layer with positive dipeptidylpeptidase IV reactivity. colonic immunoreactivity. Our results show that human ETEC bound in preference to the brush border of the enterocytic cells rather than to mucus. These results agree with those of Yamamoto et al ${ }^{2526}$ who reported that the enterocytes on formalin fixed human ileal segments are the preferential target of ETEC with $\mathrm{CFA} / \mathrm{I}$ or $\mathrm{CFA} / \mathrm{II}$ adhesins, whereas no adherence occur to $M$ cells and goblet cells. Moreover, we saw that ETEC binding developed as a function of the cell differentiation in HT29-FU cells. It is of interest to note that the expression of receptors for the ETEC virulence factors - that is, the colonisation factor antigens ${ }^{91031}$ and the heat stable cytotonic enterotoxin ${ }^{47}$ was associated with cell differentiation of the cultured human intestinal cells.

Taken altogether, the findings of Yamamoto et $a l^{526}$ and our results suggest that intestinal mucus does not influence ETEC colonisation. As our experiments, however, only explored the binding of ETEC to cells having gastric and colonic immunoreactivity, and as in vivo ETEC colonise the small intestine, ${ }^{12}$ it will be necessary to complete our study by examining the binding of ETEC to normal small intestinal mucins. It is relevant in this context that brush border glycoproteins have been reported to serve as the receptors for human ETEC. ${ }^{3133}$ This favours the idea that enterocytes rather than goblet cells or mucins are the preferred receptor. Further studies will attempt to confirm this idea and will include a comparison of mucins from HT29-MTX and HT29-FU cells with those of normal human small intestine and colon.

Supported in part by the Fondation pour la Recherche Médicale, Association pour la Recherche sur le Cancer (grant ARC to AS), Institut National de la Santé et de la Recherche Médicale and Caisse Nationale d'Assurance Maladie des Travailleurs Salariés (grant CNAMTS-INSERM to AS). SK Travailleurs Salariés (grant CNAMTS-INSERM to AS). SK
and MFB are supported by Ministère de la Recherche, de la and MFB are supported by Ministère de la Reche

Technologie et de l'Espace (doctoral fellowship). We thank T Lesuffleur and A Zweibaum (INSERM U 178,
Villejuif, France) for kindly providing us with mucus secreting Villejuif, France) for kindly providing us with mucus secreting
HT-29 cell lines. We thank D Guillaumin (Service Microscopie Electronique, CNRS, Raspail, Paris VI) for technical assistance with electron microscopy.

human mucus. ${ }^{1617}$ To our knowledge, no reports have shown the adhesion of ETEC to cultured human mucus secreting cells. As for enterocyte like cells lines, several groups have recently acquired by selection pressure mucus secreting cell subpopulations ${ }^{5} 629303839$ from the parental HT-29 Std cells. These goblets cells lines are being used to study the biochemical composition of intestinal mucus, ${ }^{4041}$ the neurohormonal control of intestinal mucus secretion, ${ }^{42} 43$ the regulation of mucus production by cytokines, ${ }^{44}$ and the mechanisms and factors that control the commitment of normal intestinal cells to the alternative types of differentiation, namely goblet or absorptive cells. ${ }^{45}$ Moreover, Micots $e t a l^{46}$ recently were first to report the attachment of an enteropathogen that is, Helicobacter pylori, to cultured human mucus secreting HT-29 $\mathrm{Cl} 16 \mathrm{E}$ cells. We examined here the attachment of ETEC to different subpopulations of HT-29 cells containing cells possessing a brush border and goblet cells, which secrete mucins of gastric or

Finlay BB, Falkow S. Common themes in microbial pathogenicity. Microbiol Rev 1990; 53: 210-30.

2 Falkow S, Isberg RR, Portnoy DA. The interaction of bacteria with mammalian cells. Annu Rev Cell Biol 1992 8: 333-63.

3 Forstner JF. Intestinal mucins in health and disease. Digestion 1978; 17: 234-63.

4 Walker WA. Role of the mucosal barrier in toxin/microbia attachment to the gastrointestinal tract. In: Microbial toxins and diarrhoeal disease. London: Pitman, Ciba Foundation Symposium 1985: 112.

5 Lesuffleur T, Barbat A, Dussaulx E, Zweibaum A. Growth adaptation to methotrexate of HT-29 human colon carcinoma cells is associated with their ability to differentiate into columnar absorptive and mucus-secreting cells. Cancer Res 1990; 50: 6334-43.

6 Lesuffleur T, Kornowski A, Luccioni C, Muleris M, Barbat A, Beaumatin J, et al. Adaptation to 5-fluorouracil of the heterogeneous human colon tumor cell line HT-29 results in the selection of cells committed to differentiation. Int 7 Cancer 1991; 49: 721-30.

7 Fogh J, Fogh JM, Orfeo T. One hundred and twenty seven cultured human tumor cell lines producing tumors in nude mice. F Natl Cancer Inst 1977; 59: 221-6.

8 Zweibaum A, Pinto M, Chevalier G, Dussaulx E, Triadou N, Lacroix B, et al. Enterocytic differentiation of a subpopulation of the human colon tumor cell line HT-29 selected for growth in sugar-free-medium and its inhibition by glucose. F Cell Physiol 1985; 122: 21-9.

9 Darfeuille-Michaud A, Aubel D, Chauvière G, Rich C, Bourges M, Servin A, et al. Adhesion of enterotoxigenic Escherichia coli to the human colon carcinoma cell line Caco-2 in culture. Infect Immun 1990; 58: 893-902. 
10 Kernéis $S$, Chauvière G, Darfeuille-Michaud A, Fourel V, Coconnier MH, Joly B, et al. Expression of receptors of enterotoxigenic Escherichia coli during enterocytic differentiation of human intestinal epithelial cells, Caco-2 and HT-29, in culture. Infect Immun 1992; 60: 2572-80.

11 Bara J, Gautier R, Daher N, Zaghouani H, Burtin P. Monoclonal antibodies against oncofetal mucin $M 1$ antigens associated with precancerous colonic mucosae. Cancer Res 1986; 46: 3983-89.

12 Lesuffleur T, Porchet N, Aubert JP, Swallow D, Gum JR, Real FX, et al. Differential expression of the human mucin genes MUC1 to MUC5 in relation to growth and differentiation of different mucus-secreting HT-29 cell subpopulations. F Cell Sci 1993; 106: 771-83.

13 Pinto M, Appay S, Simon-Assmann P, Chevalier G, Dracopoli N, Fogh J, et al. Enterocytic differenciation of cultured human colon cancer cells by replacement of glucose by galactose in the medium. Biol Cell 1982; 44 193-6.

14 Dahiya R, Lesuffleur T, Kwak K-S, Byrd JC, Barbat A, Zweibaum A, et al. Expression and characterization of mucins associated with the resistance to methotrexate of human colonic adenocarcinoma cell line HT29. Cancer Res 1992; 52: 4655-62.

15 Zweibaum A, Laburthe M, Grasset E, Louvard D. Use of cultured cell lines in studies of intestinal cell differentiation and function tion and function. In: Schultz SJ, Field M, Frizell RA, eds Handbook of physiology. The gastrointestinal system. Intestinal absorption and secretion. Vol IV.

16 Sajian SU, Forstner JF. Characteristics of binding of Escherichia coli serotype O157:H7 strain CL-49 to purified intestinal mucin. Infect Immun 1990; 58: 860-7.

17 Sajian SU, Forstner JF. Role of the putative 'link' glycopeptide of intestinal mucin in binding of piliated Escherichia coli serotype O157:H7 strain CL-49. Infect Immun 1990; 58: 868-73.

18 Mantle M, Basaraba L, Peacock SC, Gall DG. Binding of Yersinia enterocolitica to rabbit intestinal brush border membranes, mucus and mucins. Infect Immun 1989; 57 : 3292-9.

19 Paerregaard A, Espersen F, Jensen OM, Skurnik $M$ Interactions between Yersinia enterocolitica and rabbit ileal mucus: growth, adhesion, and subsequent changes in surface hydrophobicity and ability to adhere to ileal brush surface hydrophobicity and ability to adhere to ileal brush border

20 McSweegan E, Burr DH, Walker RI. Intestinal mucus gel and secretory antibody are barriers to Campylobacte jejuni to INT 407 cells. Infect Immun 1987; 55: 1431-5.

21 Tzouvelekis LS, Mentis AF, Makris AM, Spiliadis C, Blackwell C, Weir DM. In vitro binding of Helicobacter pylori to human gastric mucin. Infect Immun 1991; 59: 4252-4.

22 Yamamoto $T$, Endo $S$, Yokota $T$, Echeverria $P$. Characteristics of adherence of enteroaggregative Escherichia coli to human and animal mucosa. Infect Immun 1991; 59: 3722-39.

23 Yamamoto T, Fujita K, Yokota T. Adherence characteristics to human intestinal mucosa of Escherichia coli isolated from patients with

24 Sajian S, Reisman J, Doig P, Irvin RT, Forstner G, Forstner $J$. Binding of nonmucoid Pseudomonas aeruginosa to normal human intestinal mucin and respiratory mucin from patients with cystic fibrosis. F Clin Invest 1992; 89: 657-65.

25 Reddy MS. Human tracheobronchial mucin: purification and binding to Pseudomonas aeruginosa. Infect Immun 1992; 60: 1530-5.

26 Sajjan SU, Forstner JF. Identification of the mucin-binding adhesin of Pseudomonas cepacia isolated from patients with cystic fibrosis. Infect Immun 1992; 60: 1434-40.

27 Krogfelt J. Bacterial adhesion: genetics, biogenesis, and role in pathogenesis of fimbrial adhesins of Escherichia coli. in pathogenesis of fimbrial adhe

28 Knutton S, Lloyd DR, Candy DCA, Mc Neish AS. Adhesion of enterotoxigenic Escherichia coli to human small intestinal enterocytes. Infect Immun 1985; 48: 824-31.

29 Hafez MM, Infante D, Winawer S, Friedman E. Transforming growth factor beta-1 acts as an autocrinenegative growth regulator in colon enterocytic differentia-
tion but not in goblet cell maturation. Cell Growth Diff 1990; 1: 617-26.

30 Huet C, Sahuquillo-Merino C, Coudrier E, Louvard D. Absorptive and mucus secreting subclones isolated from a multipotent intestinal cell line (HT-29) provide new models for cell polarity and terminal differentiation. $\mathcal{F} \mathrm{Cel}$ Biol 1987; 105: 345-58.

31 Neeser JR, Chambaz A, Golliard M, Link-Amster $H$, Fryder $\mathrm{V}$, et al. Adhesion of colonization antigen factor antigen II-positive enterotoxigenic Escherichia coli strain to human enterocyte-like differentiated HT-29 cells: basis for host-pathogen interactions in the gut. Infect Immun 1989; 57: 3727-34.

32 Sporsem Oro $\mathrm{H}$, Kolsto $\mathrm{AB}$, Wenneras $\mathrm{C}$, Svennerholm AM. Identification of asialo GM1 as a binding structure for Escherichia coli colonization
Microbiol Lett 1990; 72: 289-92.

33 Wenneras C, Holmgren J, Svennerholm AM. The binding of colonization factor antigens of enterotoxigenic Escherichia coli to intestinal cell membrane proteins. FEMS Microbiol Lett 1990; 66: 107-12.

34 Kernéis $S$, Bilge $S$, Fourel V, Chauvière G, Coconnier $M H$, Servin AL. Use of purified F1845 fimbrial adhesin to study localization and expression of receptors for diffusely adhering Escherichia coli (DAEC) during enterocytic differentiation of human colon carcinoma cell lines HT-29 and Caco-2 in culture. Infect Immun 1991; 59: 4013-8.

35 Fantini J, Yahi N, Chermann JC. Human immunodeficiency virus can infect the apical and basolateral
surfaces of human colonic epithelial cells. Proc Natl Acad surfaces of human colonic

36 Superti F, Tinari A, Baldassarri L, Donelli G. HT-29 cells: a new substrate for rotavirus growth. Arch Virol 1991; 116: 159-73.

37 Neutra MR, Forstner JF. Gastrointestinal mucus synthesis, secretion and function. Johnson LR, ed. In: Physiology of the gastrointestinal tract, 2nd ed. New York: Raven Press, 1987: 975-1009.

38 Augeron C, Laboisse CL. Emergence of permanently differentiated cell clones in a human colonic cancer cell line in culture after treatment with sodium butyrate. Cancer Res 1984; 44: 3961-9.

39 Phillips TE, Heut C, Bilbo PR, Podolsky DK, Louvard D, Neutra MR. Human intestinal goblet cells in monolayer culture: characterization of a mucus-secreting subclone derived from the HT-29 colon adenocarcinoma cell line. Gastroenterology 1988; 94: 1390-403.

40 Maoret J, Font J, Augeron C, Codogno P, Bauvy C, Aubery $\mathrm{M}$, et al. A mucus-secreting human colonic cancer cell line. Purification and partial characterization of the secreted mucins. Biochem f 1989; 258: 793-9.

41 Roumagnac I, Laboisse CL. A mucus-secreting human colonic epithelial cell line responsive to cholinergic stimulation. Biol Cell 1987; 61: 65-8.

42 Laburthe M, Augeron C, Rouyer-Fessard C, Roumagnac I, Maoret JJ, Grasset E, et al. Functional VIP receptors in Maoret JJ, Grasset E, et al. Functional CL.16E. Am f Physiol (Gastrointest Liver Physiol). 1989; 256: G440-50.

43 Roomi N, Laburthe M, Fleming N, Crowther R, Forstner J. Cholera-induced mucin secretion of rat intestine: lack of effect of cAMP, cycloheximide, VIP, and colchicine Am $f$ Physiol (Gastrointest Liver Physiol) 1984; 247 G140-8.

44 Jarry A, Muzeau F, Laboisse C. Cytokine effects in a human colonic goblet cell line. Cellular damage and its partial prevention by 5 aminosalicylic acid. Dig Dis Sci 1992; 37: 1170-8.

45 Lesuffleur T, Barbat A, Luccioni C, Beaumatin J, Claire M, Kornowski A, et al. Dihydrofolate reductase gene amplification-associated shift of differentiation in methotrexatecation-associated shift of differentiation in methotre

46 Micots I, Augeron C, Laboisse CL, Muzeau F, Megraud F Mucin exocytosis: a major target for Helicobacter pylori. 7 Clin Pathol 1993; 46: 241-5.

47 Mann EA, Cohen MB, Giannella RA. Comparison of receptors for Escherichia coli heat-stable enterotoxin: novel receptor present in IEC-6 cells. Am F Physiol 1993 264: G172-8. 